\title{
TP53 gene polymorphisms at codons 11, 72, and 248 and association with endometriosis in a Brazilian population
}

C.M. Camargo-Kosugi, P. D'Amora, J.P.F.O. Kleine, C.V. Carvalho, H. Sato, E. Schor and I.D.C.G. Silva

Laboratório de Ginecologia Molecular e Proteômica, Departamento de Ginecologia, Escola Paulista de Medicina, Universidade Federal de São Paulo, São Paulo, SP, Brasil

Corresponding author: C.M. Camargo-Kosugi

E-mail: cintiakosugi@gmail.com

Genet. Mol. Res. 13 (3): 6503-6511 (2014)

Received September 10, 2013

Accepted February 3, 2013

Published August 26, 2014

DOI http://dx.doi.org/10.4238/2014.August.26.1

ABSTRACT. We evaluated the association between TP53 gene polymorphisms and endometriosis in Brazilian women. Genomic DNA was extracted from swabs of buccal cells collected from hospital patients. TP53 gene polymorphisms were investigated at three codons: $T P 53 * 11 \mathrm{Glu} / \mathrm{Gln}$ or Lys $(\mathrm{GAG}->\mathrm{CAG}$ or AAG), TP53*72 Arg/Pro (CCG->CCC), and TP53*248 Arg/Thr (CGG->TCG) using the polymerase chain reaction-restriction fragment length polymorphism method. TP53*11 presented the following genotypic distribution: the control group was $98.28 \%$ homozygous wild-type (Glu) and 1.72\% homozygous variant (Gln/Lys), and the heterozygous genotype was not identified. The genotypic distribution in the endometriosis group was $96 \%$ homozygous wild-type (Glu) and $4 \%$ heterozygous (Glu-Gln/ Lys); the homozygous variant genotype was not identified $(\mathrm{P}=0.02)$. TP53*72 showed the following genotypic distribution: the control group was $29.75 \%$ homozygous wild-type (Arg), $47.11 \%$ heterozygous (Arg-Pro), and $23.14 \%$ homozygous variant (Pro). The genotypic 
distribution in the endometriosis group was $16.15 \%$ homozygous wildtype (Arg), 51.54\% heterozygous (Arg-Pro), and 32.31\% homozygous variant (Pro) (odds ratio $=2.26 ; 95 \%$ confidence interval $=1.19-4.03$; $\mathrm{P}=0.02$ ). Only one patient had the homozygous $T P 53 * 248$ genotype (Arg-Trp/Gln); all other patients were homozygous wild-type in both the control and endometriosis groups $(\mathrm{P}=0.51$; NS). We found that $T P 53^{*} 72$ polymorphism may be associated with susceptibility to endometriosis; the presence of at least 1 polymorphic allele increased the chance of disease development by 2.26 -fold. Hence, this genetic variant is a potential candidate marker for endometriosis.

Key words: Cell cycle; Endometriosis; Gene polymorphism; p53; TP53

\section{INTRODUCTION}

Endometriosis is a benign gynecological disease defined by the presence of functional endometrial implants outside of the uterus, primarily in the pelvis, that may cause inflammatory lesions (Ulukus et al., 2006; Falconer et al., 2007). Regardless of the polygenic inheritance established, the etiology of endometriosis remains unknown (Falconer et al., 2007; Hansen and Eyster, 2010). Various patterns of cell cycle alterations such as proliferation enhancement and diminished apoptosis have been described in the context of pathophysiology for both eutopic and ectopic endometria in affected women, suggesting that this tissue displays neoplastic behavior. In addition, reported genetic polymorphisms may be responsible for the neoplastic phenotype of the endometrium and ectopic implants (Falconer et al., 2007).

p53 is one of the most important proteins controlling the cell cycle and apoptosis, acting as a gatekeeper during cell division (Levine, 1997). Proper functioning of p53 is essential for preventing tumor development, as tumor protein p53 gene (TP53) mutations are associated with instability of cell cycle progression (Loging and Reisman, 1999). p53 induces up- or downregulation of several genes involved in cell cycle progression in response to oncogenic stress or various other stresses such as DNA repair, senescence, or apoptosis (Loging and Reisman, 1999; Vogelstein et al., 2000; Vousden and Lu, 2002). Genetic characterization of human cancer has shown that $\mathrm{p} 53$ is inactivated by different types of mutations in $50 \%$ of cases (Joerger and Fersht, 2008). Thus, functional loss of the TP53 gene may be associated with tumor development and aberrant protein expression in cervical carcinoma (Zehbe et al., 1999), ovarian carcinoma (Kupryjanczyk et al., 1994), bladder cancer (Esrig et al., 1994), prostate cancer (Steiner et al., 2000), and other types of cancers (Boley et al, 2000; Miyazaki et al., 2000; Nutt et al., 2000).

The most common TP53 gene polymorphism is at codon 72 , in which an arginine to proline substitution is associated with an increased risk of tumor development (Boldrini et al., 2008; de Carvalho et al., 2008; Vieira et al., 2008; Akkiprik et al., 2009). In addition, TP53 gene polymorphisms at codons 11 and 248 are related to lung tumor (Hussain et al., 2001), ovarian cancer (Manahan et al., 2001), and acute lymphoblastic leukemia (Zhou et al., 1998).

These previous studies suggest that TP53 gene polymorphisms are associated with cell cycle aberrations, including gynecological malignances. In addition, endometriosis lesions display cell cycle disturbances and neoplastic behavior. Thus, we evaluated the association between TP53 gene polymorphisms and endometriosis in Brazilian women. 


\section{MATERIAL AND METHODS}

\section{Study population}

This transversal study was performed between January 2007 and December 2009 and included a total of 130 women with surgically and histopathologically confirmed diagnosis of endometriosis and 124 post-menopausal women without endometriosis.

The control group presented normal gynecological and pelvic ultrasonographic evaluations, and reported having no history of infertility or any gynecological condition, such as pelvic pain and/or dyspareunia, during their reproductive lives. These women were also free of endocrine-related diseases and/or cancer before and at the time of the study. The average age of the patients in the endometriosis and control groups were $34.9 \pm 7.0$ years and $58.5 \pm$ 7.8 years, respectively $(\mathrm{P}<0.0001)$.

The study was approved by the Research Ethics Committee of the Universidade Federal de São Paulo under protocol number 0856/03; all participants agreed with and signed an informed consent form.

\section{Genotype assay}

A brush used to collect buccal swabs (Cytobrush; Trumbull, CT, USA) from each patient was inserted in a tube containing $0.9 \% \mathrm{NaCl}$ solution immediately after collection.

The swabs were centrifuged at $2500 \mathrm{xg}$ for $5 \mathrm{~min}$, the supernatants were discarded, and genomic DNA was extracted from the pellets using the illustra ${ }^{\mathrm{TM}}$ blood genomicPrep Spin Kit (GE Healthcare; Piscataway, NJ, USA) according to manufacturer instructions. The polymerase chain reaction (PCR)-restriction fragment length polymorphism (RFLP) conditions used to amplify the fragments containing the TP53 codons 11, 72, and 248 have been previously described (Nutt et al., 2000).

Briefly, amplifications were carried out in a $25-\mu \mathrm{L}$ volume using a PCR standard master mix (Master Mix; Eppendorf; Hamburg, Germany). The cycling conditions varied in the annealing temperature and polymerization time used, between $55^{\circ} \mathrm{C}$ and $58^{\circ} \mathrm{C}$ and 30 and $45 \mathrm{~s}$ for $T P 53^{*} 11 / T P 53^{*} 72$ and TP53*248, respectively. General PCR conditions were: initial denaturation at $94^{\circ} \mathrm{C}$ for $5 \mathrm{~min}, 40$ cycles of denaturation at $94^{\circ} \mathrm{C}$ for $30 \mathrm{~s}$, annealing at $55^{\circ} \mathrm{C}$ or $58^{\circ} \mathrm{C}$ for $30 \mathrm{~s}$, polymerization at $72^{\circ} \mathrm{C}$ for $30 \mathrm{~s}$ or $45 \mathrm{~s}$, and final extension at $72^{\circ} \mathrm{C}$ for $7 \mathrm{~min}$. The following primer sequences were used for amplification: TP53*11: CTTGGGTTGTGGTGAAACATTG (sense) and GTCAGTCCCATGAATTTTCGCT (antisense); TP53*72: (sense) TCCCCCTTGCCGTCCCAA and CGTGCAAGTCACAGACTT (antisense); TP53*248: TAGGTTGGCTCTGACTGTACCA (sense) TGTGATGAGAGGTG GATGGGTA (antisense). These primers amplified fragments of 379 base pairs (bp) at the TP53*11 codon, 279 bp at the TP53*72 codon, and $233 \mathrm{bp}$ at the TP53*248 codon. Restriction enzyme digestion of the TP53*11 amplicon with TaqI (New England Biolabs; Ipswich, MA, USA) at $65^{\circ} \mathrm{C}$ for 30 min produced 2 fragments of $239 \mathrm{bp}$ and $140 \mathrm{bp}$, indicating the presence of the wild-type allele (Glu), whereas digestion resulting in only 1 fragment of 379 bp indicated the presence of the variant allele (Gln/Lys). Restriction enzyme digestion of the TP53*72 amplicon with BstUI (New England Biolabs) at $37^{\circ} \mathrm{C}$ for $4 \mathrm{~h}$ produced 1 fragment of $279 \mathrm{bp}$ and indicated the presence of the wild-type allele (Arg); observation of 2 fragments of 160 
bp and 119 bp indicated the presence of the variant allele (Pro). Digestion of the TP53*248 amplicon with $\mathrm{HpaII}$ (New England Biolabs) at $37^{\circ} \mathrm{C}$ for $4 \mathrm{~h}$ produced 2 fragments of $167 \mathrm{bp}$ and $69 \mathrm{bp}$, indicating the presence of the wild-type allele (Arg); observation of 1 fragment of $233 \mathrm{bp}$ indicated the presence of the variant allele (Trp/Gln).

\section{Statistical analysis}

To analyze whether the data obtained regarding the presence of genotypes as homozygous wild-type, homozygous mutant, or heterozygous mutant were in Hardy-Weinberg equilibrium, a 2 x 2 contingency table was constructed, where the null hypothesis $\left(\mathrm{h}_{0}\right)$ was given by the expected frequencies and the alternative hypothesis $\left(\mathrm{h}_{1}\right)$ was the observed frequencies for these polymorphisms. The chi-squared test $\left(\chi^{2}\right)$ was used to determine whether the sample was in Hardy-Weinberg equilibrium. A P value higher than 0.05 indicated Hardy-Weinberg equilibrium.

Analyses were performed using the SPSS software (v14.0; SPSS, Inc.; Chicago, IL, USA). The $\chi^{2}$ or Fisher exact test was used based on the variables assessed, such as frequencies and proportions. The Student $t$-test or the Mann-Whitney $U$ test was used for numerical variables. The statistical significance value was established at $5 \%(\mathrm{P}<0.05)$.

\section{RESULTS}

\section{$T P 53 * 11$ polymorphism}

A total of 241 patients were included in the TP53*11 polymorphism group. The control group presented the following genotypic distribution: $98.28 \%$ homozygous wild-type (Glu) and $1.72 \%$ homozygous variant allele (Gln/Lys); the heterozygous genotype was not identified. The genotypic distribution in the endometriosis group was $96 \%$ homozygous wildtype (Glu) and 4\% heterozygous (Glu-Gln/Lys); the homozygous variant genotype was not identified $(\mathrm{P}=0.02)$. Table 1 represents the panel of TP53 gene polymorphism frequencies. Evaluation of the TP53*11 polymorphism based on the allelic distribution and considering only the wild-type (Glu) and variant alleles (Gln/Lys) showed no statistical differences between groups $(\mathrm{P}=0.54)$.

\section{TP53*72 polymorphism}

A total of 251 patients were included in the TP53*72 polymorphism group. The control group presented the following genotypic distribution: $29.75 \%$ homozygous wild-type (Arg), 47.11\% heterozygous (Arg-Pro), and 23.14\% homozygous for the allele variant (Pro). The genotypic distribution in the endometriosis group was $16.15 \%$ homozygous wild-type (Arg), 51.54\% heterozygous (Arg-Pro), and 32.31\% homozygous for the variant allele (Pro) $(\mathrm{P}=0.02)$. Values for the presence of the allele encoding Pro in the minimal/mild endometriosis group were $23.68 \%$ and $48.91 \%$ in the moderate and severe groups, respectively ( $\mathrm{P}$ $<0.0003$ ). The comparative allelic frequencies of the TP $53 * 72$ polymorphism between the minimal/mild and moderate/severe endometriosis groups are represented in Table 2. 
TP53 gene polymorphism and endometriosis in Brazilian women

6507

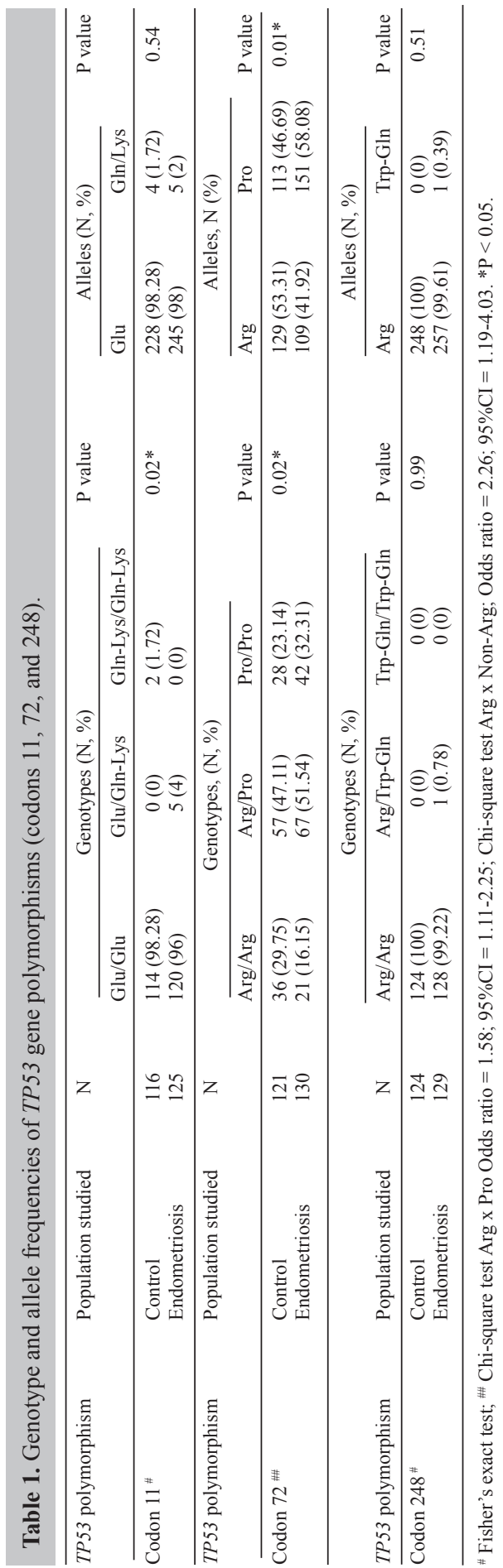

Genetics and Molecular Research 13 (3): 6503-6511 (2014) 
Table 2. Allele frequencies of TP53 gene polymorphism at codon 72 between endometriosis groups.

\begin{tabular}{llcccc}
\hline TP53 polymorphism & Population studied & \multicolumn{3}{c}{ Allele frequencies (N, \%) } & \multirow{2}{*}{ P value } \\
\cline { 2 - 4 } & & $\mathrm{N}$ & $\mathrm{Arg}$ & $\mathrm{Pro}$ & \\
\hline Codon 72 & Minimal/mild endometriosis & 76 & $58(76.31)$ & $18(23.69)$ & $<0.0003^{* * *}$ \\
& Moderate/severe endometriosis & 184 & $94(51.09)$ & $90(48.91)$ & \\
\hline
\end{tabular}

Chi-square test; odds ratio $=3.08 ; 95 \% \mathrm{CI}=1.68-5.63 . * * * \mathrm{P}<0.001$.

\section{TP53*248 polymorphism}

Only 1 patient in the TP53*248 polymorphism group, the endometriosis group, presented a heterozygous genotype (Arg-Trp/Gln); all the other participants had the homozygous wild-type genotype in both the control and endometriosis groups $(\mathrm{P}=0.51)$.

\section{DISCUSSION}

The search for a genetic marker of endometriosis is important for increasing the possibility of early diagnosis. Currently, there are no markers that can be used to predict this disease; hence, early diagnoses are rare. In addition, clarification of various aspects of the pathogenesis of this disease, also guided by potential markers, may improve future diagnosis and treatment prospects.

Cell cycle aberrations have being described in topic and ectopic endometria in women with endometriosis in recent years (Velarde et al., 2009; Schor et al., 2009; Aghajanova et al, 2010). Because this may be due to genetic alterations such as polymorphisms, some studies were performed to evaluate polymorphisms in genes that encode proteins involved in cell cycle control; however, the results of these studies have been inconclusive. Fernandéz et al. (2005) studied the FAS and FASL genes; Hsieh and Lin (2006) evaluated $P 21^{\text {wafl }}$ gene polymorphisms. These studies reported no differences in polymorphism frequencies between women with and without endometriosis (Fernández et al., 2005; Hsieh and Lin, 2006; Velarde et al., 2009; Schor et al, 2009; Aghajanova et al., 2010). However, other studies showed significant differences in the prevalence of gene polymorphisms that encode proteins involved in regulating the cell cycle (Fernández et al., 2005; Hsieh and Lin, 2006; Velarde et al., 2009; Schor et al., 2009; Aghajanova et al., 2010). Camargo-Kosugi et al. (2009) reported a 2.0-fold increase in the likelihood of endometriosis in women who carried at least 1 variant allele in the $P 27$ gene.

A study of TP53 gene mutation and its association with endometriosis, first performed by Vercellini et al. (1994) involving only 10 women, showed no differences in polymorphism frequencies between women with or without the disease. Similarly, no differences were reported in other studies performed in Japanese (Omori et al., 2004) and Italian women (Lattuada et al., 2004; Vietri et al., 2007; Ammendola et al., 2008).

A study conducted in Taiwan was the only study describing differences in the TP53 gene polymorphism at codon 72 in patients with and without endometriosis (Hsieh and Lin, 2006). This study reported genotype prevalence rates of 9.5\% for wild-type (Arg-Arg), 66.2\% for heterozygous (Arg-Pro), and $24.3 \%$ for homozygous (Pro) genotypes in the experimental group (endometriosis), as well as $30.7 \%$ for wild-type (Arg-Arg), $50 \%$ for the heterozygous mutant (Arg-Pro), and 19.3\% for the homozygous mutant in the control group. These results 
are similar to those of the present study in which the following prevalence rates were observed in the endometriosis group: $16.15 \%$ for wild-type (Arg-Arg), $51.54 \%$ for the heterozygous alleles (Arg-Pro), and $32.31 \%$ for the homozygous (Pro) alleles, as well as $29.75 \%$ for wild-type (Arg-Arg), 47.11\% for the heterozygous variant (Arg-Pro), and $23.14 \%$ for the homozygous variant in the control group.

It has been well established that different ethnic backgrounds are associated with different genetic polymorphisms. This may explain the differences between the results obtained in this current study and those of Lin et al. (1994) and Hsieh and Lin (2006), among others (Omori et al., 2004; Lattuada et al., 2004; Vietri et al., 2007; Ammendola et al., 2008). A study involving a larger population sample size may confirm these data.

It is important to emphasize that this study included women at the mean age ( \pm standard deviation, SD) of $58.5 \pm 7.8$ years in the control group. These women were within an age range indicative of past reproductive life; they reported the absence of any symptoms that may be related to endometriosis, such as pelvic pain and/or dyspareunia, no infertility history and no long-term estrogen treatments. Therefore, despite difference in the mean age between the groups compared in this study, the control group participants presented a reduced chance of developing endometriosis. The $\mathrm{A} / \mathrm{G}$ polymorphism in the follicle-stimulating hormone receptor gene was studied in Taiwanese women using a control group composed of postmenopausal women (Wang et al., 2011). In other studies that included younger women in the control groups, it was unknown whether these women, regardless of reporting no history of pelvic disease (Riiskjaer et al., 2011) or neonates (Ammendola et al., 2008), would develop endometriosis in the future.

Brazilian women included in the present study were from a multiracial population. Because many diseases are associated with different ethnicities, the inclusion of women from a multiracial population resulted in a more comprehensive study. Furthermore, the evaluation of Hardy-Weinberg equilibrium validated the sample population in this study, indicating that no allele was underrepresented.

TP53 is a major tumor suppressor gene capable of responding to several stress signals (Vogelstein et al., 2000). Activation of this gene may stop cell cycle progression and induce senescence and apoptosis, which may prevent malignant cell proliferation, inhibition of tumor growth, repair of genomic damage, and elimination of potential oncogenic cells (Nakayama et al., 2001). The wild-type p53 protein functions as a transcription factor that activates tumor suppressor genes including P21, MDM2, GADD45, and Bax. These proteins are necessary for the regulation and progression of the cell cycle or apoptosis as responses to DNA damage (Loging and Reisman, 1999). In addition, functional loss of the $\mathrm{p} 53$ protein may be associated with the development of tumors in approximately $50 \%$ of all human solid tumors including several gynecological tumors (Kupryjanczyk et al., 1994; Zehbe et al., 1999).

The results reported by Hsieh and Lin et al. (2006) regarding the Glu11 polymorphism corroborate the results obtained in this study: the presence of the wild-type allele Glu11 was observed in $96 \%$ of women in the endometriosis group and $98.28 \%$ in the control group. Despite the statistically significant difference observed in this study, the relative rarity of this mutation indicates that it may not play a relevant role in endometriosis pathogenesis (Hsieh and Lin, 2006; Aghajanova et al., 2010). The TP53 gene polymorphism at codon $248\left(T P 53^{*} 248\right)$ was reported in several studies of solid tumors (Lin et al., 1994; Hussain et al., 2001; Wang et al., 2001). Nevertheless, in the present study, no statistically significant difference was detected. 
However, a significant difference between groups was observed in the TP53*72 gene polymorphism. When comparing the Arg-Arg genotype (homozygous wild-type) with genotypes showing at least 1 variant allele (Arg-Pro and Pro-Pro), the mutation was significantly more frequent in the endometriosis group than in the control group. These results suggest that the presence of only 1 mutated allele increases the chances of developing endometriosis disease by more than 2 -fold [odds ratio $(\mathrm{OR})=2.26 ; 95 \%$ confidence interval $(\mathrm{CI})=1.19-4.03$; $\mathrm{P}=0.02]$. Furthermore, the association was also evident in the comparison of allele distributions of Arg and Pro in patients with moderate-to-severe endometriosis $(\mathrm{OR}=3.08 ; 95 \% \mathrm{CI}=$ $1.68-5.63 ; \mathrm{P}=0.0003)$.

In conclusion, the $T P 53^{*} 72$ polymorphism was more frequently observed in the endometriosis group than in the control group. The TP53*72 polymorphism may be associated with susceptibility to endometriosis; therefore, the presence of at least 1 polymorphic allele could double a patient's chance of developing the disease. Hence, this genetic variant may be a marker of endometriosis.

\section{ACKNOWLEDGMENTS}

Research supported by a FAPESP grant (\#09/53000-2). We are grateful to Professor Eduardo M. Kosugi, MD, PhD and Tatiana C.S. Bonetti, PhD, Universidade Federal de São Paulo for statistical analysis.

\section{REFERENCES}

Aghajanova L, Horcajadas JA, Weeks JL, Esteban FJ, et al. (2010). The protein kinase A pathway-regulated transcriptome of endometrial stromal fibroblasts reveals compromised differentiation and persistent proliferative potential in endometriosis. Endocrinology 151: 1341-1355.

Akkiprik M, Sonmez O, Gulluoglu BM, Caglar HB, et al. (2009). Analysis of p53 gene polymorphisms and protein overexpression in patients with breast cancer. Pathol. Oncol. Res 15: 359-368.

Ammendola M, Gloria-Bottini F, Sesti F, Piccione E, et al. (2008). Association of p53 codon 72 polymorphism with endometriosis. Fertil. Steril. 90: 406-408.

Boldrini L, Gisfredi S, Ursino S, Lucchi M, et al. (2008). Prognostic impact of p53 Pro72 homozygous genotype in nonsmall cell lung cancer patients. Oncol. Rep. 19: 771-773.

Boley SE, Anderson EE, French JE, Donehower LA, et al. (2000). Loss of p53 in benzene-induced thymic lymphomas in p53+/- mice: evidence of chromosomal recombination. Cancer Res. 60: 2831-2835.

Camargo-Kosugi CM, da Silva ID, Sato H, D'Amora P, et al. (2009). The V109G polymorphism in the p27 gene is associated with endometriosis. Eur. J. Obstet. Gynecol. Reprod. Biol. 145: 180-183.

de Carvalho CR, da Silva ID, Pereira JS, de Souza NC, et al. (2008). Polymorphisms of p53, GSTM1 and GSTT1, and HPV in uterine cervix adenocarcinoma. Eur. J. Gynaecol. Oncol. 29: 590-593.

Esrig D, Elmajian D, Groshen S, Freeman JA, et al. (1994). Accumulation of nuclear p53 and tumor progression in bladder cancer. N. Engl. J. Med. 331: 1259-1264.

Falconer H, D'Hooghe T and Fried G (2007). Endometriosis and genetic polymorphisms. Obstet. Gynecol. Surv. 62: 616-628.

Fernandez RM, Noval JA, Garcia-Lozano JC, Borrego S, et al. (2005). Polymorphisms in the promoter regions of FAS and FASL genes as candidate genetic factors conferring susceptibility to endometriosis. Int. J. Mol. Med. 15: 865-869.

Hansen KA and Eyster KM (2010). Genetics and genomics of endometriosis. Clin. Obstet. Gynecol. 53: 403-412.

Hsieh YY and Lin CS (2006). P53 codon 11, 72, and 248 gene polymorphisms in endometriosis. Int. J. Biol. Sci. 2: 188193.

Hussain SP, Amstad P, Raja K, Sawyer M, et al. (2001). Mutability of p53 hotspot codons to benzo(a)pyrene diol epoxide (BPDE) and the frequency of p53 mutations in nontumorous human lung. Cancer Res. 61: 6350-6355.

Joerger AC and Fersht AR (2008). Structural biology of the tumor suppressor p53. Annu. Rev. Biochem. 77: 557-582. 
Kupryjanczyk J, Bell DA, Yandell DW, Scully RE, et al. (1994). p53 expression in ovarian borderline tumors and stage I carcinomas. Am. J. Clin. Pathol. 102: 671-676.

Lattuada D, Vigano P, Somigliana E, Abbiati A, et al. (2004). Analysis of the codon 72 polymorphism of the TP53 gene in patients with endometriosis. Mol. Hum. Reprod. 10: 651-654.

Levine AJ (1997). p53, the cellular gatekeeper for growth and division. Cell 88: 323-331.

Lin SR, Lee YJ and Tsai JH (1994). Mutations of the p53 gene in human functional adrenal neoplasms. J. Clin. Endocrinol. Metab. 78: 483-491.

Loging WT and Reisman D (1999). Elevated expression of ribosomal protein genes L37, RPP-1, and S2 in the presence of mutant p53. Cancer Epidemiol. Biomarkers Prev. 8: 1011-1016.

Manahan KJ, Taylor DD and Gercel-Taylor C (2001). Clonal heterogeneity of p53 mutations in ovarian cancer. Int. J. Oncol. 19: 387-394.

Miyazaki T, Kato H, Shitara Y, Yoshikawa M, et al. (2000). Mutation and expression of the metastasis suppressor gene KAI1 in esophageal squamous cell carcinoma. Cancer 89: 955-962.

Nakayama K, Toki T, Zhai YL, Lu X, et al. (2001). Demonstration of focal p53 expression without genetic alterations in endometriotic lesions. Int. J. Gynecol. Pathol. 20: 227-231.

Nutt CL, Noble M, Chambers AF and Cairncross JG (2000). Differential expression of drug resistance genes and chemosensitivity in glial cell lineages correlate with differential response of oligodendrogliomas and astrocytomas to chemotherapy. Cancer Res. 60: 4812-4818.

Omori S, Yoshida S, Kennedy SH, Negoro K, et al. (2004). Polymorphism at codon 72 of the p53 gene is not associated with endometriosis in a Japanese population. J. Soc. Gynecol. Investig. 11: 232-236.

Riiskjaer M, Nielsen K, Steffensen R, Erikstrup C, et al. (2011). Association of interleukin-10 promoter polymorphism and endometriosis. Am. J. Reprod. Immunol. 65: 13-19.

Schor E, da Silva ID, Sato H, Baracat EC, et al. (2009). P27Kip1 is downregulated in the endometrium of women with endometriosis. Fertil. Steril. 91: 682-686.

Steiner MS, Zhang X, Wang Y and Lu Y (2000). Growth inhibition of prostate cancer by an adenovirus expressing a novel tumor suppressor gene, pHyde. Cancer Res. 60: 4419-4425.

Ulukus M, Cakmak H and Arici A (2006). The role of endometrium in endometriosis. J. Soc. Gynecol. Investig. 13: 467476.

Velarde MC, Aghajanova L, Nezhat CR and Giudice LC (2009). Increased mitogen-activated protein kinase kinase/ extracellularly regulated kinase activity in human endometrial stromal fibroblasts of women with endometriosis reduces 3', 5'-cyclic adenosine 5'-monophosphate inhibition of cyclin D1. Endocrinology 150: 4701-4712.

Vercellini P, Trecca D, Oldani S, Fracchiolla NS, et al. (1994). Analysis of p53 and ras gene mutations in endometriosis. Gynecol. Obstet. Invest 38: 70-71.

Vieira JO, da Silva ID, Higo PE, Nogueira-de-Souza NC, et al. (2008). Study of p53 codon 72 polymorphism in patients with breast cancer. Eur. J. Gynaecol. Oncol. 29: 364-367.

Vietri MT, Molinari AM, Iannella I, Cioffi M, et al. (2007). Arg72Pro p53 polymorphism in Italian women: no association with endometriosis. Fertil. Steril. 88: 1468-1469.

Vietri MT, Molinari AM, Iannella I, Cioffi M, et al. (2007). Arg72Pro p53 polymorphism in Italian women: no association with endometriosis. Fertil. Steril. 88: 1468-1469.

Vogelstein B, Lane D and Levine AJ (2000). Surfing the p53 network. Nature 408: 307-310.

Vousden KH and Lu X (2002). Live or let die: the cell's response to p53. Nat. Rev. Cancer 2: 594-604.

Wang HS, Cheng BH, Wu HM, Yen CF, et al. (2011). A mutant single nucleotide polymorphism of follicle-stimulating hormone receptor is associated with a lower risk of endometriosis. Fertil. Steril. 95: 455-457.

Wang JY, Lin SR, Hsieh JS, Hsu CH, et al. (2001). Mutations of p53 gene in gastric carcinoma in Taiwan. Anticancer Res. 21: 513-520.

Zhou M, Gu L, Yeager AM and Findley HW (1998). Sensitivity to Fas-mediated apoptosis in pediatric acute lymphoblastic leukemia is associated with a mutant p53 phenotype and absence of Bcl-2 expression. Leukemia 12: 1756-1763. 